\title{
Herramientas técnicas y principios básicos en el proceso de planificación turística de los sitios patrimoniales
}

María José Viñals | Centro de Investigación Arquitectura, Patrimonio y Gestión para

el Desarrollo Sostenible, Universitat Politècnica de València

URL de la contribución <www.iaph.es/revistaph/index.php/revistaph/article/view/4969>

\section{RESUMEN}

Este trabajo tiene como objetivo identificar las herramientas técnicas y buenas prácticas que deben tenerse en cuenta para la planificación turística de sitios y/o elementos del patrimonio natural y cultural, especialmente en la fase de puesta en valor de los mismos. Además, se analizan los principios básicos para garantizar una adecuada y ética implementación de las mismas.

Este tema se inscribe en el contexto de la necesidad de planificar y gestionar el turismo en sitios patrimoniales desde una perspectiva de conservación y protección de los bienes, desde el reconocimiento de la importancia del patrimonio como motor de desarrollo local, y desde la necesidad de crear productos turísticos de calidad, responsables y respetuosos con su entorno natural, cultural y social que además satisfagan las expectativas de los visitantes.

La metodología de trabajo se ha centrado especialmente en la Investigación de las Ciencias del Diseño, ya que a partir de la detección de problemas en sitios y destinos turísticos patrimoniales, se presentan resultados de soluciones (herramientas técnicas) que ya han sido aplicadas con éxito y evaluadas por el equipo investigador a lo largo del desarrollo de numerosos proyectos en diversos países tanto en espacios naturales como en sitios culturales.

\section{Palabras clave}

Buenas prácticas | Destinos turísticos | Herramientas técnicas | Patrimonio cultural | Patrimonio natural | Planificación | Puesta en valor | Principios técnicos | Principios éticos | Sitios patrimoniales | Turismo | 


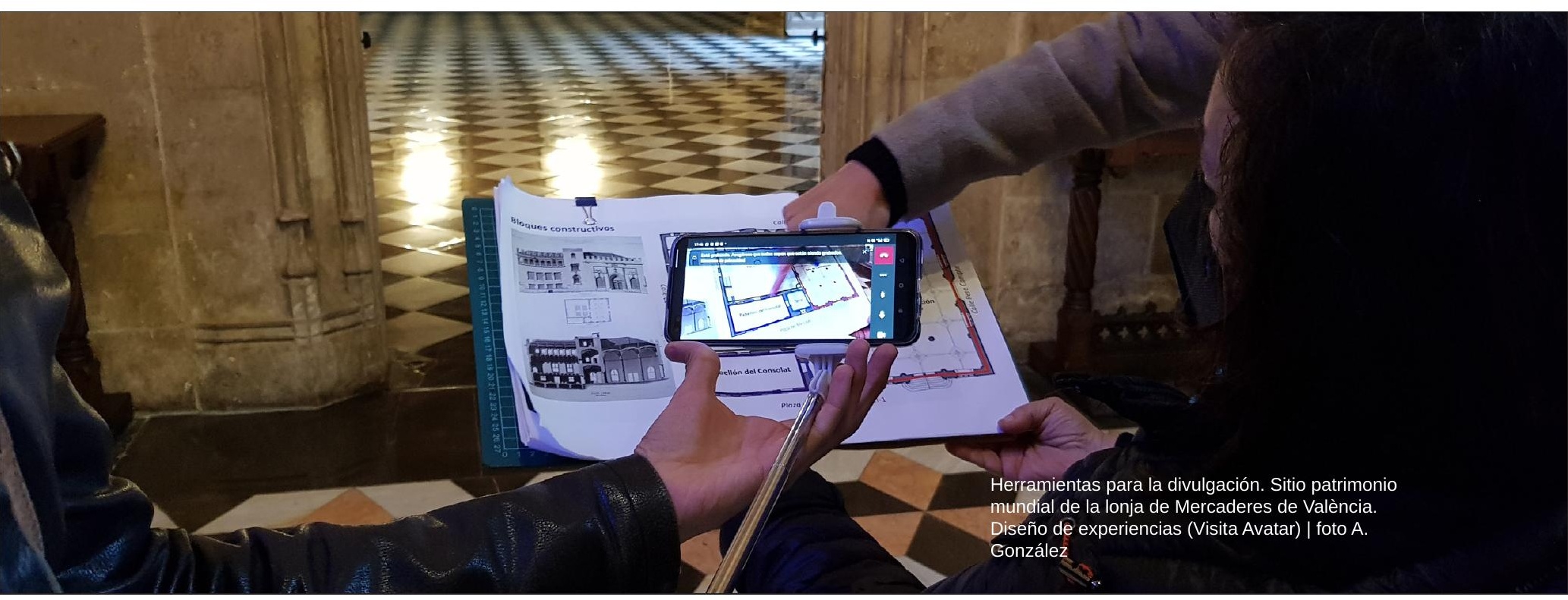

\section{Technical Tools and basic principles in Tourism Planning of Heritage Sites}

\section{ABSTRACT}

This paper aims to identify the technical tools and best practices that should be taken into account for tourism planning of natural and cultural heritage sites, especially in the enhancement phase. In addition, it discusses the basic principles to ensure their proper and ethical implementation.

The context in which this topic is framed is the need to plan and manage tourism in heritage sites from a perspective of conservation and protection of the assets, from the recognition of the importance of heritage assets as a driver of local development, and from the need to create quality tourism products that are responsible and respectful of their natural, cultural and social environment and that also meet the expectations of visitors.

The work methodology has focused especially on Design Science Research, since, based on the detection of problems in heritage tourism sites and destinations, the results of solutions (technical tools) are presented that have already been successfully applied and evaluated by the research team throughout the development of numerous projects in different countries, both in natural and cultural sites.

\section{Key words}

Best Practices | Tourism | Planning Tools | Enhancement Tools | Cultural Heritage | Natural Heritage | Technical Principles | Ethical Principles | Heritages Sites | Tourism |

Cómo citar: Viñals Blasco, M.J. (2021) Herramientas técnicas y principios básicos en el proceso de planificación turística de los sitios patrimoniales. Revista $\mathrm{PH}, \mathrm{n} .{ }^{\circ}$ 104, 2021, pp. 104-125 <www.iaph.es/revistaph/index.php/revistaph/article/view/4969> DOI 10.33349/2021.104.4969

Enviado: 18/06/2021 | Aceptado: 19/07/2021 | Publicado: 01/10/2021 


\section{INTRODUCCIÓN}

El auge del turismo patrimonial basado en importantes recursos naturales y culturales desde hace décadas ha brindado a muchos lugares la oportunidad de diversificar su oferta recreativa y su economía. Sin embargo, la presencia de activos naturales y culturales excepcionales no garantiza por sí sola la presencia de visitantes y turistas. Paralelamente, hemos asistido a la devastación y degradación de algunos sitios patrimoniales debido a la falta o inadecuación de una planificación turística sostenible basada en la rigurosidad técnica y la profesionalidad.

La planificación turística de bienes o sitios patrimoniales de alto valor se aborda desde una doble perspectiva. En primer lugar, debe garantizar a largo plazo la conservación de los recursos; en segundo lugar, el patrimonio debe contemplarse como un elemento de dinamización socioeconómica de las sociedades que lo albergan. Por ello, se necesita llevar a cabo un proceso de planificación basado en herramientas técnicas y en una implementación coherente y eficiente de las mismas, con fundamentos técnicos y éticos. La causa estriba en la exigencia de afrontar nuevos paradigmas emergentes de gestión y la salvaguarda del patrimonio en un contexto de gran presión turística sobre los atractivos patrimoniales.

Hay que señalar que la planificación y la gestión sostenibles del turismo supone uno de los retos más acuciantes en relación con el futuro de la Convención del Patrimonio Mundial, por lo que resulta un objetivo crucial del Programa de Patrimonio Mundial y Turismo Sostenible de la Unesco (2011). Otras instituciones como la Organización Mundial del Turismo (OMT), el Consejo Internacional de Monumentos y Sitios (ICOMOS), la Unión Internacional para la Conservación de la Naturaleza (UICN) y muchas otras llevan tiempo identificando la necesidad de desarrollar herramientas de mejora para la planificación y gestión turística como forma de garantizar la conservación de los elementos y sitios patrimoniales y también para ofrecer, a su vez, una visita de calidad a la altura del valor excepcional universal de los sitios.

Las herramientas de planificación turística del patrimonio no están, generalmente, consideradas de forma integral en los manuales técnicos; habitualmente se encuentra información académica sobre el desarrollo específico de planes de gestión turística para sitios patrimoniales. Resulta más frecuente la publicación de trabajos científicos dedicados a buenas prácticas de planificación y gestión turística a partir de casos de estudio y también el desarrollo y aplicación individualizada de herramientas (inventarios de atractivos, catálogos de protección, etc.) y trabajos que abordan medidas correctivas para reconducir situaciones no deseadas (estudios de capacidad de carga recreativa, análisis de impactos sobre los recursos, estudio de frecuentación y movilidad de los flujos de visitantes, etc.). Pese a la relevan- 


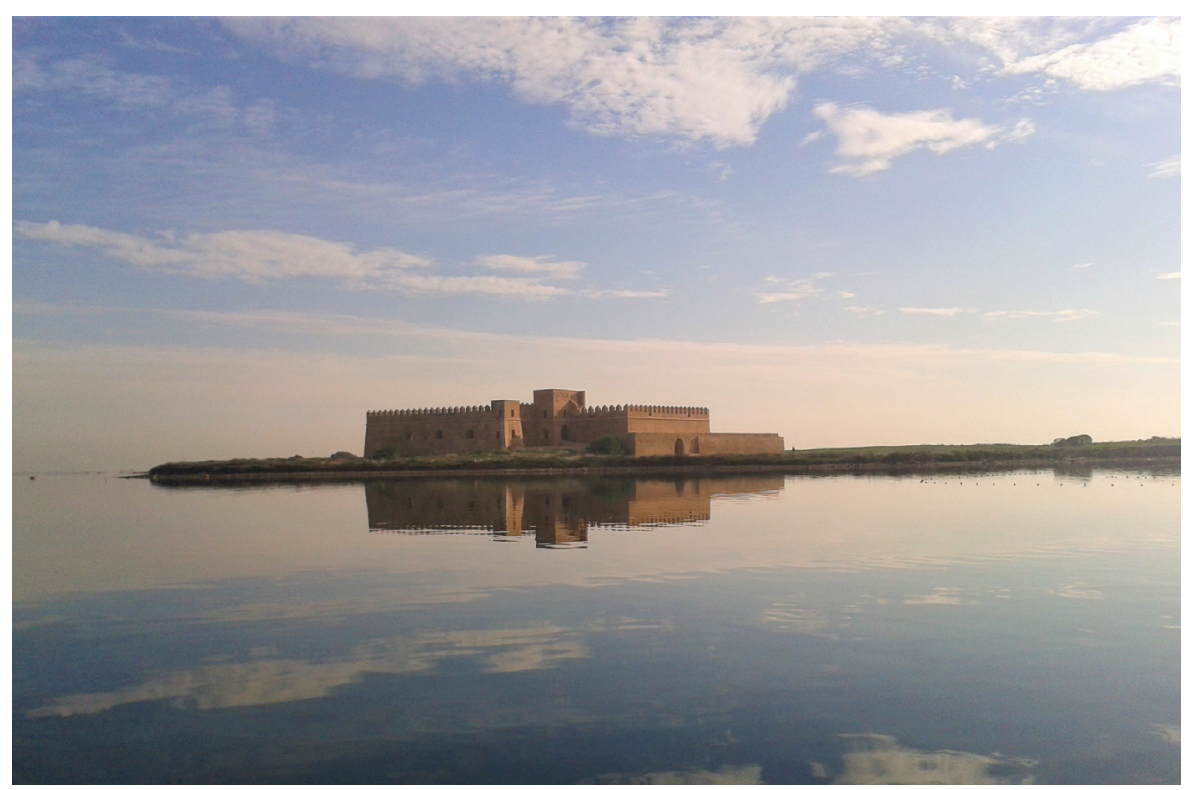

cia del tema, hay que decir que no ha sido hasta el siglo XXI cuando se ha abordado científicamente de forma integral el tema del diseño y análisis de herramientas de planificación y gestión turística de elementos patrimoniales. Como antecedente a esta situación, tenemos los trabajos de Hall y McArthur (1998) y el de Wight (1998) que abordaron enfoques y herramientas generales que tienen el potencial de abordar importantes cuestiones de planificación y gestión del turismo sostenible en relación con los recursos naturales y culturales. Ya en el siglo XXI, y con un carácter integrador, destaca, como institución pionera en el estudio y desarrollo conceptual de herramientas de planificación turística de elementos patrimoniales, la Unesco. Pedersen, experto vinculado a esta institución, publicó en 2002 Managing Tourism at World Heritage Sites: a Practical Manual for World Heritage Site Managers, un trabajo muy completo y de referencia en este ámbito. El Programa de Naciones Unidas para el Medio Ambiente, junto con la Organización Mundial de Turismo (UNEP y UNWTO 2005), llevó a cabo una labor muy relevante también en este contexto en los primeros años de este siglo. Posteriormente, la Unesco (s.f.) editó un manual online de herramientas de gestión turística y De Ascaniis et ál. incidieron de nuevo en el tema de la planificación y gestión de sitios patrimoniales en trabajos encargados por la Unesco (De Ascaniis, Gravari-Barbas y Cantoni 2018). En este contexto, hay que mencionar el manual desarrollado por el Departamento de Medioambiente y Patrimonio del Gobierno Australiano (2008) que destaca por su carácter práctico y aplicado en el abordaje de este tema. En España, destacan los trabajos de Martos Molina (2016) y el de Viñals et ál. (2017) que presentan también un manual práctico que desarrolla las diferentes herramientas de planificación y gestión turística del patrimonio.
Isla de Chikly y fuerte de Santiago, Túnez. Valoración de la capacidad de carga recreativa (herramienta de planificación) | foto I. MartínezSanchís 
Basándose en la experiencia adquirida en el desarrollo de proyectos de planificación turística de sitios patrimoniales y, en aras de secuenciar ordenadamente el proceso la planificación, la autora de este trabajo agrupa las diversas herramientas en tres grandes bloques:

a) las herramientas de conservación y protección;

b) las herramientas de puesta en valor turístico;

c) las herramientas de dinamización socioeconómica.

Una correcta planificación y gestión del patrimonio debe seguir esta secuencia lógica y ordenada de acciones; por tanto, no se puede desarrollar el proceso de puesta en valor turístico ni de dinamización socioeconómica si previamente no se han establecido los mecanismos de conservación y protección.

En el primer bloque, están las herramientas propias de los especialistas de cada una de las disciplinas específicas de acuerdo con el tipo de patrimonio (arqueológico, arquitectónico, ecológico, urbanístico, etc.) y existe una literatura científica muy razonable como para abordar su aplicación. También se incluye en este grupo las herramientas de protección jurídica (normativas, políticas de patrimonio, registro del patrimonio, etc.) que son tratadas por los expertos en los aspectos legales del patrimonio. Existe mucha bibliografía sobre cómo desarrollar planes de conservación y gestión del patrimonio. El plan director constituye uno de los instrumentos más habituales aunque, por el momento, en España, no tiene consideración normativa y se encuentra en

Ciudad colonial de Gracias (Lempira) en Honduras. Diseño del patrón de la visita en el centro histórico una situación de indefinición legal. Los instrumentos de protección si están | foto M.J. Viñals
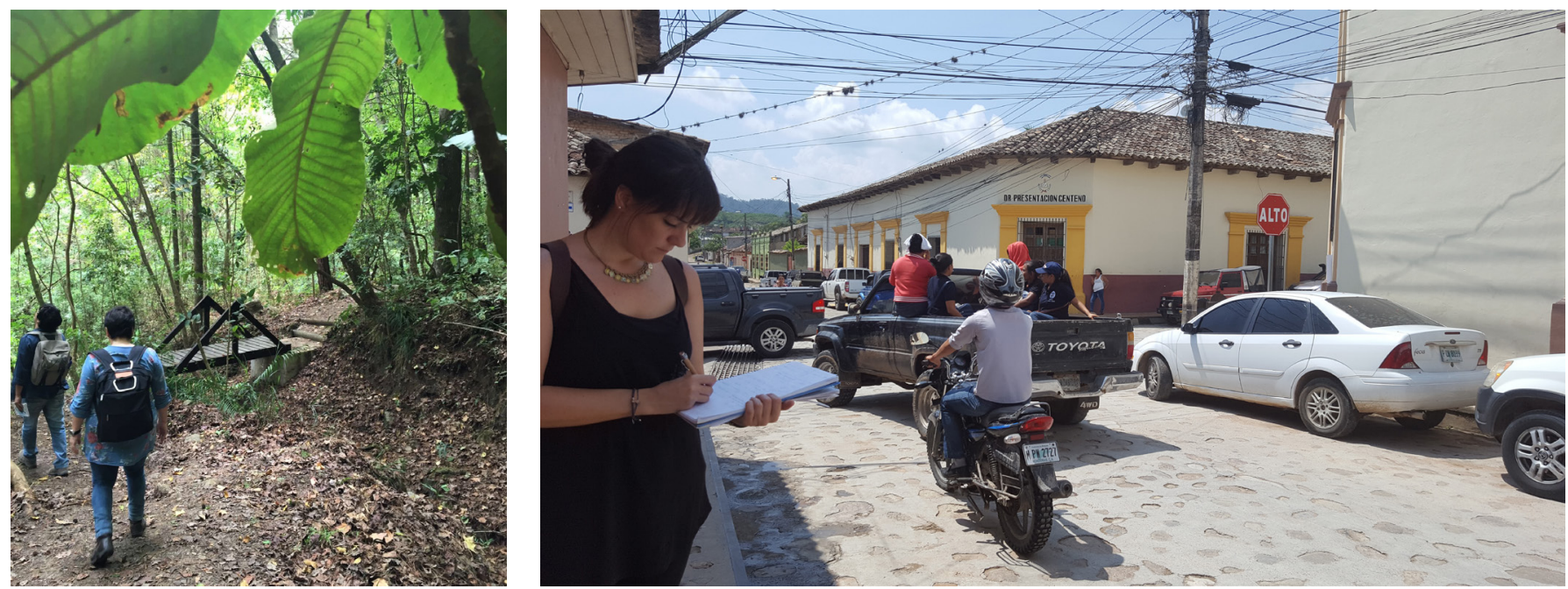
fijados amparándose en la normativa patrimonial y la urbanística (estatal, autonómica y local). Así, tenemos bienes de interés cultural (BIC) recogidos en la Ley de Patrimonio Histórico Española de 25 de junio de 1985, bienes protegidos por inventarios y catálogos autonómicos, los catálogos urbanísticos de protecciones y los planes especiales de protección, ambos de carácter municipal.

Las herramientas de puesta en valor turístico que se incluyen en el segundo bloque son aquellas que facilitan la transformación de los recursos naturales y culturales en atracciones turísticas. Este proceso resulta muy abstracto si no se concreta en la aplicación de una serie de instrumentos técnicos que conduzcan finalmente a la posibilidad de abrir las puertas al público para la visita. Pearce (1991) y posteriormente Gunn (2002) describen este proceso cuando se refieren a los atractivos turísticos como aquellos lugares o sitios que se planifican y gestionan para el desarrollo de actividades recreativas y el disfrute de los visitantes. A ellos, se suman las interesantes aportaciones de Richards y Munsters (2010) sobre los métodos de investigación en turismo cultural. Hay que señalar, no obstante que, desde una perspectiva técnica, se detecta una falta de profesionales de alto nivel en este campo del conocimiento ya que no existe habitualmente, al menos en nuestro país, una oferta formativa universitaria especializada en este tema (Viñals y Teruel 2021). El análisis de este bloque de herramientas de puesta en valor y los principios asociados a su implementación va a ser el foco de atención de este trabajo.

En relación al papel del patrimonio como dinamizador de la economía local, hay que destacar que los recursos naturales y culturales son uno de los hitos identitarios de muchas comunidades locales y la base para movilizar
Herramientas de planificación:

Señalización de itinerarios ecuestres en el Parque Natural del Túria, València | foto M.J. Viñals

Marjal de Gandia, València. Diseño de senderos accesibles | foto M. Oñorbe
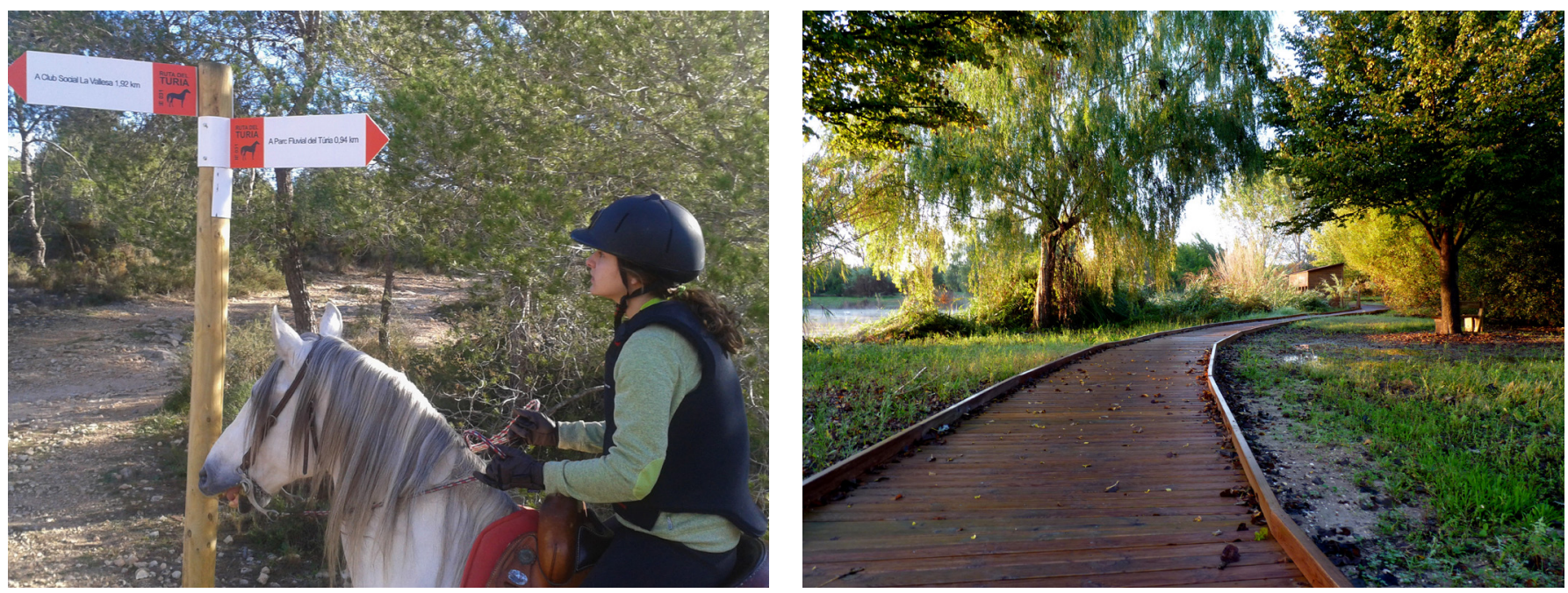
la economía de ciertos territorios. Este estímulo ha ido normalmente de la mano del sector turístico, que, con mayor o menor acierto, ha actuado como catalizador en el desarrollo de algunos lugares. Por ello, en este bloque las herramientas estarán enfocadas a facilitar las relaciones que se establecerán entre el sector turístico y las administraciones responsables de los bienes. Hay que comentar que se trata de un tema cada vez más consolidado (Baycan y Girard 2011; Lähdesmäki 2014; Historic England 2018; Della Spina 2019). Las investigaciones recientes y los proyectos en curso demuestran que la dinamización de áreas protegidas, zonas históricas y la salvaguardia del patrimonio cultural pueden abordarse conjuntamente y aportar importantes beneficios económicos a las comunidades locales. La Organización para la Cooperación y el Desarrollo Económicos y el Consejo Internacional de Museos han analizado los impactos positivos que la cultura tiene sobre el desarrollo local (OCDE e ICOM 2019) y han dado las claves de cómo maximizar el valor social y económico del patrimonio. También ha sido una estrategia emprendida por la Unión Europea, ya que el patrimonio se considera como un recurso cultural contemporáneo y vivo, por lo que se entiende que su conservación y puesta en valor abre considerables oportunidades de desarrollo local y regional. Entre las medidas importantes, se encuentra la comunicación de la Comisión sobre la necesidad de un enfoque integrado del patrimonio cultural (Comisión Europea 2014) en donde se destacan las diferentes herramientas transversales con las que cuenta la UE para apoyar la protección y la valorización intrínseca y social del patrimonio con el objetivo de facilitar el crecimiento económico y la creación de empleo.

Desde el punto de vista del patrimonio natural, se observa que ya el Plan Estratégico del Convenio sobre la Diversidad Biológica 2011-2020 y las Metas de Aichi (UNEP y CBD 2010) y la Estrategia de Biodiversidad de la UE hasta 2020 (Comisión Europea 2011) señalaban que el patrimonio natural y la biodiversidad son importantes factores de bienestar, de crecimiento socioeconómico y de articulación territorial. En cuanto al patrimonio cultural, hay que destacar la Declaración de París sobre el Patrimonio como Motor

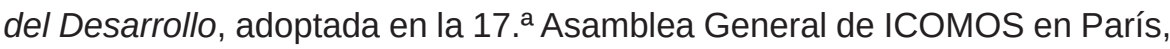
Francia (ICOMOS 2011a). Además, la cultura también fue incluida, por primera vez, dentro de los Objetivos de Desarrollo Sostenible de la Agenda de Desarrollo Sostenible 2030 durante la 70. a Asamblea General de la ONU (Organización de Naciones Unidas 2015). Hay que mencionar que uno de los ejemplos más notorios del desarrollo socioeconómico asociado al patrimonio deriva de la reutilización de edificios históricos, ya que está comprobado que proporciona una base para la regeneración de muchas ciudades y territorios (Pendlebury y Porfyriou 2017). Esta estrategia ha sido liderada por administraciones públicas tales como la Cámara de los Comunes del Reino Unido (House of Commons 2004). Así, se observa en la conclusión del Parliamentary Select Committee que ya estudiaba el papel de los edificios históricos en la regeneración urbana. 
Por estas razones, la planificación y puesta en valor del patrimonio como atractivo turístico adquiere una importancia estratégica para los destinos (Bowitz y lbenholt 2009) y muchas de las convocatorias públicas sobre patrimonio y subvenciones para proyectos centran sus objetivos en estas cuestiones.

La hipótesis de partida de este trabajo se fundamenta pues en el hecho de que usar responsablemente los elementos patrimoniales supone un acicate para su conservación, para el mantenimiento de la identidad cultural de un territorio y para generar riqueza económica. Sin embargo, la clave de todo se encuentra en "el uso responsable" que se haga de los bienes. Por ello, este artículo tiene como objetivo dar a conocer una serie de herramientas de puesta en valor que han sido ya experimentadas con éxito y garantizan una utilización turística racional y respetuosa del patrimonio.

\section{METODOLOGÍA}

Este trabajo se enmarca en los métodos de investigación cualitativa y se ha basado en una revisión bibliográfica sobre el proceso de puesta en valor turístico del patrimonio desde una perspectiva integrada y en el marco de la planificación y conservación preventiva de los sitios patrimoniales. Se considera oportuno desarrollar este proceso como un sistema integral de apoyo al desarrollo de la planificación y gestión turística porque, tal como apuntan Reitsamer y Brunner-Sperdin (2015), los visitantes perciben los sitios como un todo, de forma holística.

Como el objetivo principal de este trabajo se centra en identificar un sistema de herramientas, el método seguido ha sido el de la Investigación de la Ciencia del Diseño (Aken 2004) que se enmarca en la investigación prescriptiva. Por lo tanto, los resultados presentados, han sido fruto de aplicar las cinco etapas sugeridas por este autor -1) identificar el problema; 2) comprender el problema; 3) desarrollar una solución; 4) implementar la solución; y 5) evaluar la solución- en diversos sitios patrimoniales, tanto naturales como culturales a lo largo de estos años.

\section{RESULTADOS}

\section{Sistema de herramientas de puesta en valor turístico}

El proceso de puesta en valor turístico del patrimonio, como ya se ha mencionado, se integra en una estrategia general de planificación y gestión de los elementos patrimoniales individualmente o a nivel de un destino patrimonial (territorio). Se caracteriza por ser un procedimiento integral, flexible que 
Borj El Loutani, Ghar El Melh, Túnez. Reutilización de edificio histórico para Centro Nacional de Humedales | foto M.J. Viñals

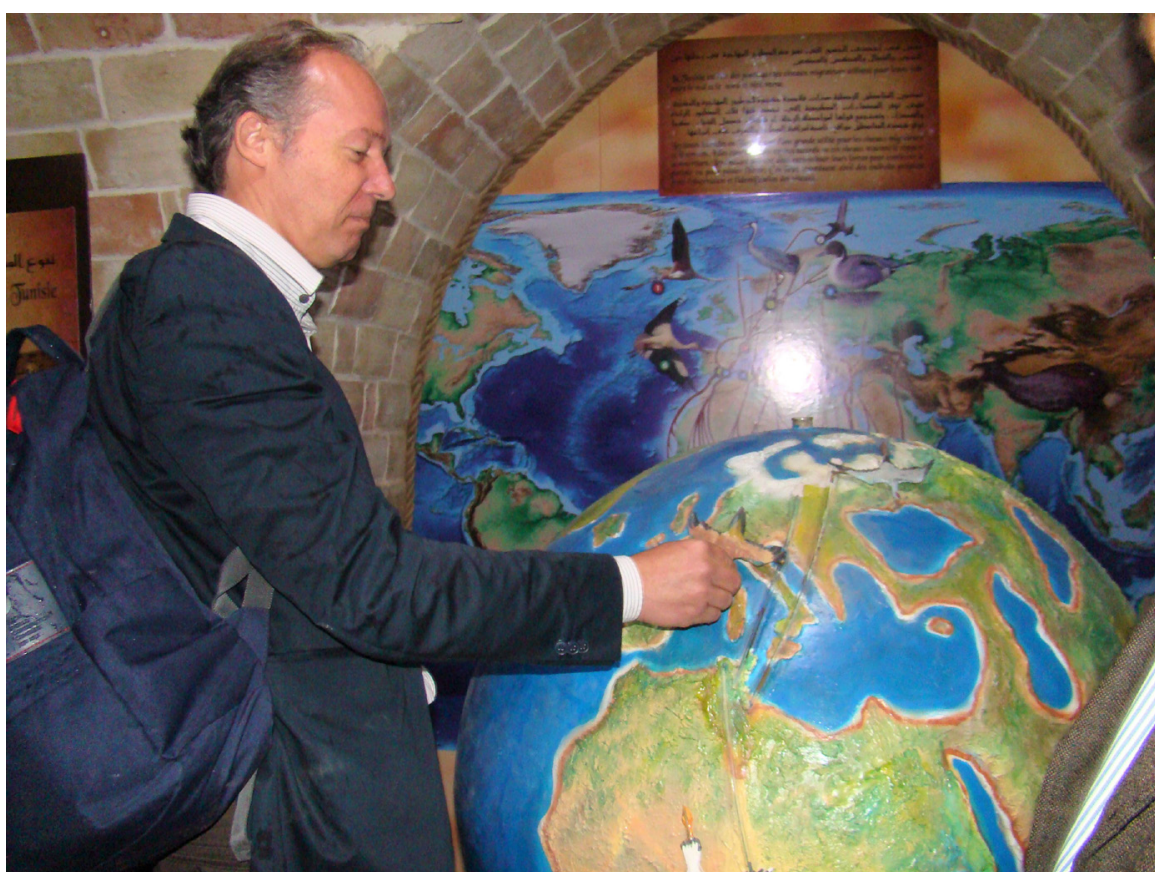

puede adaptarse a las especificidades de contextos complejos, además de permitir interactuar con conocimientos heterogéneos e incorporar los valores locales asociados a los diferentes sitios.

Hay que señalar la existencia de manifiestas reservas que muchos gestores del patrimonio muestran cuando las administraciones planean desarrollar actividades turísticas en los sitios patrimoniales. Se pueden señalar muchos ejemplos de sitios patrimoniales de gran valor en los que desarrollos turísticos inadecuados han provocado el deterioro, a veces irreversible, de elementos de gran valor. No hay que olvidar, por ejemplo, que después de designarse un sitio como Patrimonio Mundial, la popularidad del lugar aumenta y, por lo tanto, el interés por visitarlo también (Yang y Lin 2014). Por estas razones, la Unesco considera actualmente que abordar la gestión eficaz del turismo en los sitios, de forma coherente con la protección, la conservación y la gestión del valor universal excepcional, forma parte de las nominaciones (UNESCO 2011). Peltier (2017) señalaba que la mitad de los sitios designados como Patrimonio Mundial no tenían plan de gestión turística y no llevaban a cabo acciones suficientes para evitar los impactos negativos del turismo de masas. Por tanto, como se observa es, en estos momentos, una acción prioritaria que se ha de emprender en los sitios patrimoniales.

El proceso de puesta en valor se inicia con un análisis preciso de las condiciones de partida del sitio o elemento para disponer de una valoración patri- 
monial ex-ante y de las actividades recreativas y factores que intervienen en los sitios. De esta manera, se podrá conocer cuáles serán las herramientas que se han de implementar y con qué prioridad. Estas herramientas están pensadas para ser instrumentos de gestión preventiva, pero, en muchas ocasiones, se aplican como medidas correctoras una vez que aparecen problemas por falta o inadecuada planificación.

Basándonos en estudios previos y en el desarrollo de proyectos empíricos llevados a cabo por el equipo de investigación, en la tabla de la p. 115 se proponen las herramientas de puesta en valor agrupadas según su propósito.

Entre las herramientas de planificación del lugar, se incluyen aquellas de aplicabilidad a un territorio en su conjunto y las que se desarrollan específicamente en un sitio individualizado (monumento, yacimiento arqueológico, museo, etc.). El Inventario de elementos patrimoniales constituye la más básica y fundamental de todas las herramientas, ya que incluye toda la información relacionada con el elemento patrimonial. Además, a partir de los inventarios se desarrollan otras herramientas, entre ellas, las legales de protección. La información contenida en un inventario debe estar actualizada para que funcione como una herramienta eficaz.

Para llevar a cabo la toma de decisiones en relación a la puesta en valor de los elementos patrimoniales, se ha de proceder a su evaluación, tanto desde un punto de vista de sus valores y atributos inherentes ${ }^{1}$ (Valoración intrínseca del patrimonio), como desde el punto de vista turístico (Valoración turística del patrimonio), si va a asumir la visita pública u otras actividades recreativas.

Según Viñals et ál. (2017), los principales criterios para evaluar el valor intrínseco son: la significancia, la representatividad, la singularidad, la naturalidad/integridad, la autenticidad y la contextualización. La significancia es el criterio más importante utilizado por la Unesco para evaluar el valor universal excepcional de los elementos del patrimonio (UNESCO 2005). Para la valoración turística se utilizarán: atractividad, resistencia (versus fragili$\mathrm{dad} /$ vulnerabilidad), disponibilidad, accesibilidad in situ, viabilidad y valores educativos. Hay que señalar que un alto valor intrínseco del recurso no tiene por qué coincidir con un alto valor turístico. Así, por ejemplo, un recurso con una alta significancia ecológica, histórica o social puede no resultar atractivo para los visitantes.

A nivel de destino turístico, el Estudio de las infraestructuras, transportes y servicios básicos, así como conocer los Prestatarios de servicios turísticos que operan en la zona resulta fundamental ya que sin su presencia la actividad turística no existiría, aunque hubiera importantes atractivos patrimoniales.
1

Un recurso natural, por ejemplo, puede ser evaluado desde la perspectiva geológica, geomorfológica, geográfica, hidrológica, paleontológica, biológica, ecológica y/o astronómica, entre otros, mientras que un elemento cultural puede ser evaluado desde el punto de vista arquitectónico, arqueológico, urbanístico, etnográfico, artístico, histórico, sociocultural, científico, tecnológico, etc. 
En cuanto a las herramientas que se aplican a elementos específicos están la Viabilidad técnica, legal y económica del uso recreativo que analiza las posibilidades de reutilización adaptativa para el uso recreativo de un bien patrimonial. La Zonificación y usos potenciales, el Análisis del acceso físico al sitio, la Valoración de la capacidad de carga recreativa y el Diseño del patrón de la visita tienen un marcado carácter espacial y están en la base del diseño de otras herramientas relacionadas con la gestión de visitantes. La Capacidad de carga recreativa es problamente la herramienta de mayor reconocimiento y aplicación y sobre la que más literatura científica existe desde que Stankey y Manning (1986) consolidaron este concepto en la gestión de espacios naturales. Por otra parte, el elemento patrimonial debe proporcionar un acceso ordenado y adecuado mediante el desarrollo de un Patrón de la visita al espacio físico, de manera que se proponga un recorrido o itinerario y así se eviten situaciones de congestión y desagrado a los visitantes y, también, impactos inadecuados en zonas sensibles. Estos aspectos se encuentran muy relacionados con la gestión de la capacidad de carga en el lugar.

La Predicción y valoración de impactos al patrimonio resulta fundamental para garantizar la conservación del sitio. La herramienta formal Evaluación de impacto ambiental (EIA) se utiliza para la identificación y para la evaluación de los impactos en recursos naturales. También está la Evaluación de impacto patrimonial (EIP) realizada para los bienes culturales (ICOMOS 2011b), aunque su práctica se encuentra menos extendida. Desde el punto de vista de la puesta en valor turístico, conviene evaluar anticipadamente los efectos negativos potenciales de la actividad; es decir, proceder a un análisis de predicción de los impactos sobre el patrimonio y así, la mitigación de los mismos estará integrada en el diseño de las actividades turísticas. Hay países como Australia que establecen directrices muy valiosas al respecto (Australian Government 2019).

Sobre el Diseño de experiencias recreativas hay que señalar que una experiencia va más allá de una actividad recreativa; el enfoque pretende crear una conexión emocional entre el bien patrimonial y los visitantes. Por ello debe planificarse cuidadosamente (Carballo et ál. 2015; Kim y Fesenmaier 2015; Scott, Gao, y Ma 2017; Moscardo 2019). La experiencia debe resultar especial, espectacular y memorable ya que constituye el componente más creativo de la oferta y la verdadera motivación para que los turistas y excursionistas visiten un destino; además, proporciona identidad turística a un lugar. El desarrollo de experiencias y actividades turísticas requiere de la existencia de ciertos servicios y equipamientos básicos y recreativos (Diseño de equipamientos recreativos) para garantizar la seguridad, confort y disfrute de los visitantes. Por otra parte, las experiencias turísticas deben adecuarse al territorio y sus recursos. En su diseño se debe considerar la accesibilidad universal, el menor impacto sobre los recursos y prever las medidas pre- 


\begin{tabular}{|c|c|c|}
\hline \multirow[b]{2}{*}{ CATEGORÍA } & \multicolumn{2}{|c|}{ HERRAMIENTAS } \\
\hline & Destino (territorio) & $\begin{array}{c}\text { Sitio patrimonial } \\
\text { (edificio, parque natural, etc.) }\end{array}$ \\
\hline Planificación del lugar & $\begin{array}{l}\text { Inventario de elementos patrimoniales. } \\
\text { Valoración Intrínseca del patrimonio. } \\
\text { Valoración turística del patrimonio. } \\
\text { Estudio de infraestructuras, transportes y } \\
\text { servicios. } \\
\text { Inventario prestatarios de servicios turísti- } \\
\text { cos. }\end{array}$ & $\begin{array}{c}\text { Viabilidad técnica y legal del uso recreativo. } \\
\text { Zonificación y usos potenciales. } \\
\text { Análisis del acceso físico al sitio. } \\
\text { Valoración de la capacidad de carga } \\
\text { recreativa. } \\
\text { Diseño del patrón de la visita. } \\
\text { Predicción y valoración de impactos al } \\
\text { patrimonio. } \\
\text { Diseño de experiencias recreativas. } \\
\text { Diseño de equipamientos recreativos. } \\
\text { Análisis del potencial turístico de las expe- } \\
\text { riencia recreativas. }\end{array}$ \\
\hline Gestión de visitantes & \multicolumn{2}{|c|}{$\begin{array}{c}\text { Análisis de la demanda potencial. } \\
\text { Análisis de confort psicológico de los visitantes. } \\
\text { Estudio de frecuentación, distribución y movilidad de los flujos. } \\
\text { Programa de interpretación del patrimonio. } \\
\text { Plan de uso público } \\
\text { (regulación de la visita pública, protocolo para la atención de visitantes, plan de emergen- } \\
\text { cias, protocolo de bioseguridad). }\end{array}$} \\
\hline $\begin{array}{c}\text { Divulgación y comunicación } \\
\text { estratégica }\end{array}$ & \multicolumn{2}{|c|}{$\begin{array}{l}\text { Plan de comunicación estratégica. } \\
\text { Campañas de sensibilización y de apoyo. } \\
\text { Formación especializada de los profesionales. }\end{array}$} \\
\hline
\end{tabular}

ventivas necesarias, como se comentaba anteriormente. Existe numerosa bibliografía sobre buenas prácticas en la construcción de estos equipamientos como los trabajos de Beyer et ál. (2005) y Andaroodi (2020).

La herramienta Análisis del potencial turístico ayuda a identificar la capacidad que la actividad recreativa tiene para dinamizar socioeconómicamente una zona o territorio; es decir, las posibilidades que tiene para convertirse en producto turístico comercializable. La UNWTO (s.f.) define producto turístico como una combinación de elementos tangibles e intangibles (recursos naturales, culturales y artificiales), los equipamientos, servicios y las actividades recreativas integradas en una experiencia global que tiene un precio de mercado y se vende a través de canales de distribución. Por ello, esta herramienta debe considerarse como un instrumento clave para orientar la toma de decisiones de las políticas de inversión pública. Se centrará pues en analizar el potencial de los atractivos existentes de la zona, la accesibilidad general y la existencia de prestatarios de servicios.

Entre las herramientas de gestión de visitantes se incluyen: Análisis de la demanda potencial, Análisis de confort psicológico de los visitantes, Estudio de frecuentación, distribución y movilidad de los flujos, Programa de inter-
Tabla 1. Herramientas de puesta en valor turístico para sitios patrimoniales.

Las herramientas de planificación son de aplicación tanto a un territorio como a un elemento individualizado. Se separan para hacer hincapié en aquellas que son más adecuadas en cada caso. 

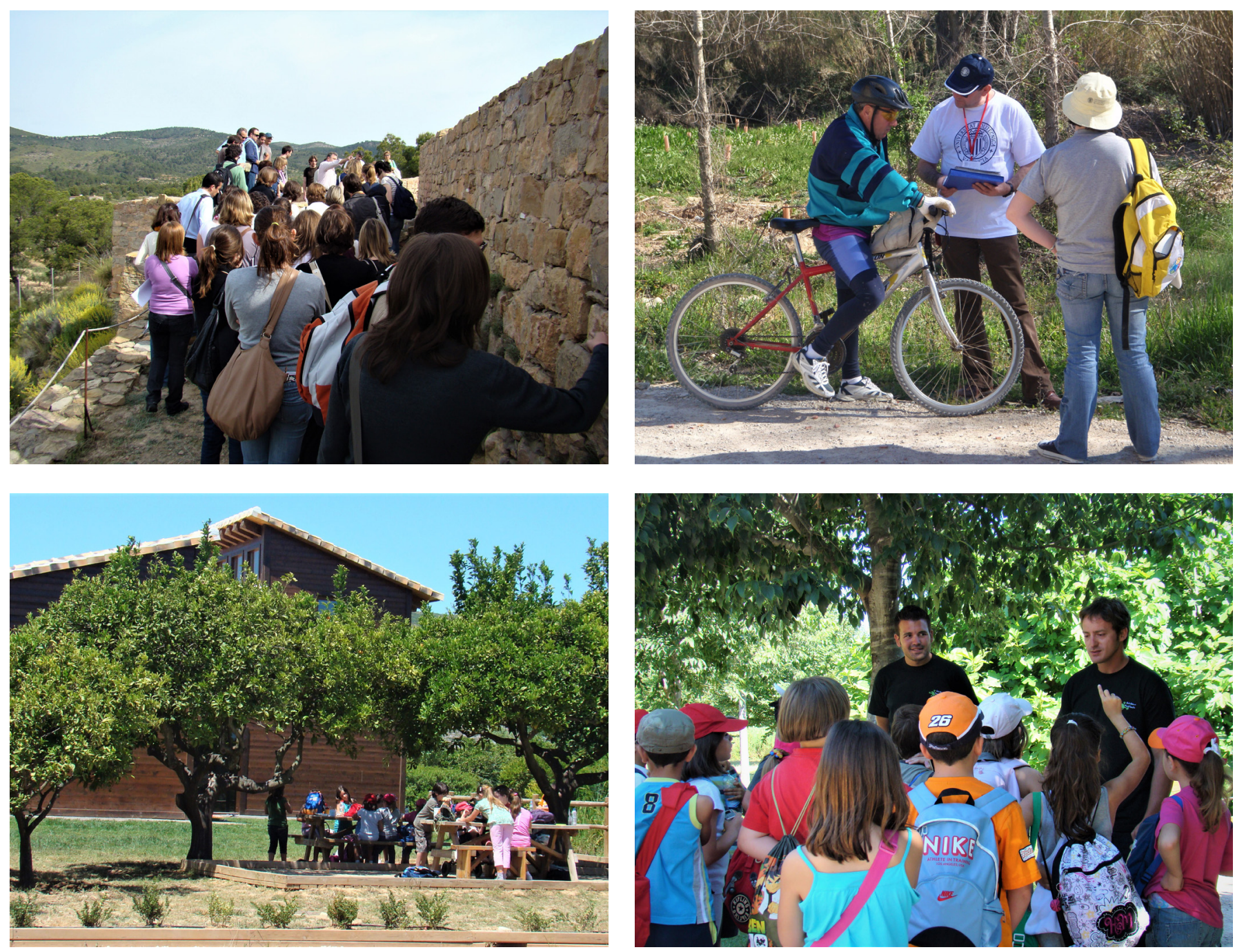

Herramientas de gestión de visitantes:

De izquierda a derecha y de arriba abajo, yacimiento ibero del Castellet de Bernabé, Llíria, València. Estudio de capacidad de carga recreativa

Parque Natural del Túria, València. Análisis de frecuentación y distribución del flujo de visitantes

Aula Natura, Gandia, València. Diseño centro de interpretación y equipamientos recreativos

Marjal de Gandia, València. Programa de interpretación del patrimonio | fotos M. J. Viñals pretación del patrimonio, Plan de uso público, Regulación de la visita pública, Protocolo para la atención de visitantes, Plan de emergencias y Protocolo de bioseguridad.

Los estudios sobre Frecuentación, distribución y movilidad de los flujos de visitantes se realizan para hacer un seguimiento de las personas (volumen de visitantes, comportamientos y movimientos, etc.), conocer los lugares que transitan y los momentos clave (franjas horarias) en que desarrollan la actividad recreativa en un atractivo o destino turístico. Se realizan con carácter correctivo cuando se detectan problemas de congestión o saturación de capacidad de carga de un atractivo o de un equipamiento (centro de interpretación, un sendero, etc.). Por otra parte, hay que recordar que el itinerario derivado del diseño del patrón de visitantes es el escenario donde se realiza 
el seguimiento y recuento de los mismos y la observación de sus comportamientos y movimientos. Eagles y McCool (2002) señalaron que se trata de un tema importante relacionado con la gestión en la mayoría de los parques naturales.

La herramienta Análisis de confort psicológico de los visitantes se centra en identificar y analizar los factores que influyen en la experiencia recreativo-turística (Viñals, Morant y Teruel 2014) y que estas autoras agrupan en:

a) físico-fisiológicos (especialmente bioclimáticos y factores de seguridad);

b) factores propios del lugar (percepción del entorno), tales como espacio geográfico (abierto, cerrado), atractivos, experiencia turística, desarrollo de la actividad (patrón de la visita, tamaño de grupo, nivel de frecuentación, etc.);

c) factores relacionados con los equipamientos y los servicios (especialmente con los servicios básicos, accesos, información e interpretación);

d) factores relacionados con los visitantes (perfil sociodemográfico, rasgos de personalidad, motivaciones, expectativas, comportamientos, etc.).

Este análisis está estrechamente ligado al Diseño de la experiencia turística y al Análisis de demanda potencial. Esta última herramienta se refiere al conjunto de personas que, individual o colectivamente, se encuentran motivadas por una serie de productos o servicios de un destino turístico con el objetivo de satisfacer sus necesidades. En los estudios de demanda turística, se diferencia en la demanda efectiva o real (número actual de personas que viajan al destino) y la demanda potencial (quienes podrían visitar el lugar en el futuro para realizar actividades turísticas). Ambos se pueden desarrollar basándose en un atractivo individual o en un destino turístico en su conjunto.

El instrumento Programa de interpretación del patrimonio resulta clave pues permite al visitante acercarse intelectual $\mathrm{y}$, sobre todo, emocionalmente al patrimonio. Muchas instituciones y administraciones públicas (Unesco, ICOMOS, UICN, US National Association for Interpretation, US National Park Service, Interpret Europe, entre otras) así lo han asumido y promueven activamente su uso en los procesos de puesta en valor del patrimonio. Uno de los principales objetivos de la interpretación del patrimonio consiste en establecer relaciones significativas entre el público y los elementos del patrimonio (Ham 1992; Beck y Cable 1998; Buschholz et ál. 2015). Para ello, se utilizan numerosas técnicas, medios y actividades, pero siempre sobre la base de proporcionar una experiencia auténtica y memorable basada en emociones y sentimientos que persigan el desarrollo de actitudes y comportamientos de respeto y valoración del patrimonio (Tilden 1957). 
Por otra parte, están los Planes de uso público, que no deben confundirse con los Planes de gestión turística, ya que estos últimos implican la consideración de los aspectos de dinamización socioeconómica y deben abordarse en una fase posterior de la planificación. Los primeros tienen como objetivo definir las condiciones en las que se llevarán a cabo las actividades recreativas en un espacio patrimonial y las líneas directrices sobre la gestión de los visitantes. Pueden ejecutarse de forma integral o segmentarse en diversos documentos como la Regulación de la visita pública, un Protocolo de atención de visitantes, un Plan de emergencias para saber cómo gestionar situaciones complejas en donde puede estar en riesgo la seguridad de los visitantes, y también un Protocolo de bioseguridad orientado a la gestión del atractivo en situaciones de riesgo de salud pública. Con ocasión de la reciente pandemia del coronavirus SARS-CoV-2, numerosos organismos de ámbito internacional (Ministerio de Cultura y Deporte. Dirección General de Bellas Artes 2020; Instituto para la Calidad Turística Española 2020; International Council of Museums 2020a, 2020b; Ministerio de Cultura y Deporte. Instituto del Patrimonio Cultural de España 2020) han incidido en la necesidad de dotarse de este protocolo en los sitios patrimoniales.

Respecto a las herramientas de comunicación estratégica y divulgación, hay que destacar el Plan de comunicación estratégica que tiene un claro carácter promocional y dinamizador. La divulgación del patrimonio resulta crucial ya que, como apunta ICOMOS (2011a), conocer es la base para crear sentimiento de orgullo para las personas y un deseo de implicarse en la protección y mejora del patrimonio. En el caso de los elementos patrimoniales públicos, la comunicación corresponde a las instituciones. Así, la administración pública tiene una responsabilidad social de informar. Los planes de comunicación incluyen estrategias y acciones comunicativas e identifican los medios para divulgar el patrimonio (offline y online). Es necesario seleccionar los más adecuados para cada tipo de audiencia teniendo en cuenta el presupuesto disponible.

Las campañas de sensibilización son herramientas específicas de comunicación estratégica que intentan influir en la percepción, creencias, actitudes y comportamientos de la población y cambiar políticas y estrategias en relación a la concienciación y comprensión sobre la conservación y protección del patrimonio y otros temas asociados con el desarrollo turístico. También constituyen una estrategia relevante de las políticas educativas. Estas campañas pueden dedicarse a públicos diversos (público en general, escolares, etc.) y se recomiendan especialmente para las personas encargadas de la toma de decisiones. Las instituciones internacionales relacionadas con el patrimonio dedican una gran atención al desarrollo de estas campañas ya que están en la propia esencia de su existencia. Existen numerosas actividades para llevar a cabo campañas de sensibilización como se puede observar en el trabajo de Shimray (2019), algunas de ellas muy creativas. 
En cuanto a la Formación especializada de profesionales, tal como define ICOMOS (2011), pretende formar a los principales actores con las capacidades necesarias para la conservación, protección, planificación y gestión turística del patrimonio. Como se mencionaba al inicio, se ha detectado la necesidad de disponer de profesionales bien preparados en el desarrollo e implementación de estas herramientas, y esto debería suponer una prioridad en los programas educativos universitarios dedicados al patrimonio.

\section{Principios básicos en la implementación de las herramientas de puesta en valor}

Las herramientas presentadas llevan años implementándose a tenor de las necesidades surgidas en los destinos y se han ido mejorando siguiendo el método heurístico del ensayo y error. Como se presentaba en el apartado de metodología, este trabajo responde a este tipo de proceso, donde se identifica un instrumento (solución), se ensaya y se mejora, tanto proposicional como procedimentalmente. Se ha analizado en apartados anteriores sucintamente el desarrollo técnico de las herramientas que, después de una fase de buenas prácticas, han logrado ya definitivamente erigirse como instrumentos técnicos. Desde el punto de vista procedimental hay que considerar también una serie de principios básicos, sobre todo, en fase de implementación, que garanticen el buen devenir y la ética del proceso.

De esta manera, el principio rector que debe regir todo proceso de diseño e implementación de herramientas de puesta en valor turístico es el de sostenibilidad. La sostenibilidad de un destino turístico se define como la capacidad del territorio para acoger población (visitante y residente) sin poner en peligro la viabilidad de sus subsistemas naturales, económicos y sociales, ni su aptitud adaptativa y de recuperación (resiliencia), cuando éstos sean sometidos a los esfuerzos derivados del proceso de desarrollo turístico (UNESCO 2014; Manrique, Tazim y Warden 2016). El Programa de Naciones Unidas para el Medio Ambiente junto con la Organización Mundial de Turismo (UNEP y UNWTO 2005) Ilamaron la atención sobre este principio y esbozaron una serie de requerimientos básicos para sugerir cómo se debía darle cumplimiento. Hay que recordar que la sostenibilidad se encuentra fuertemente relacionada con la conservación y protección de los recursos patrimoniales y la preservación de su integridad y autenticidad; por lo tanto, se trata de un principio fundamental que hay que seguir en el desarrollo de un destino turístico a largo plazo. En este sentido, Labadi et ál. (2021) han elaborado para ICOMOS unas líneas directrices para la aplicación de los objetivos de desarrollo sostenible en la gestión del patrimonio.

Adicionalmente, se sugiere adoptar una serie de principios de carácter técnico como: calidad de la información, rigor científico, enfoque integral, actualización, adaptabilidad y versatilidad, y eficacia. De esta manera, hemos de 
tener en cuenta el carácter genérico y flexible de las herramientas propuestas. Pueden considerarse como un sistema completo que puede utilizarse en su totalidad, o aplicarse parcialmente como herramientas específicas y adaptadas para mejorar aspectos concretos de la gestión patrimonial o de los visitantes. Partiendo de un modelo estándar, se han de diseñar y desarrollar específicamente para un lugar concreto, ya que las situaciones de partida y necesidades de los sitios pueden ser muy diferentes. Con todo, su desarrollo debe concebirse a partir de información veraz y de calidad, y siguiendo un método de trabajo científico y riguroso, lo cual garantizará la credibilidad, fiabilidad, y solidez de su aplicación. El rigor científico incluye la evaluación de los resultados. Por ello, será necesaria la consideración de indicadores. El Sistema Europeo de Indicadores Turísticos para la gestión sostenible de destinos (ETIS) (Unión Europea 2017) es un ejemplo de estas buenas prácticas. Este sistema se ha desarrollado para ayudar a medir el rendimiento y productividad de los destinos turísticos en relación con la sostenibilidad.

Se hará siempre necesario un enfoque integral, aunque se implementen herramientas de forma individualizada, ya que así se velará por la coherencia y por una visión holística, que considere los factores multidimensionales que intervienen en la planificación turística y que deben enmarcarse en el contexto general del ordenamiento territorial, la conservación patrimonial y la gestión de los visitantes. Además de todo esto, hay que tener en cuenta que el territorio es un sistema dinámico que evoluciona, por lo que habrá que estar pendiente de una actualización regular de los datos que permita una retroalimentación y evaluación permanente del sitio para poder tomar las decisiones adecuadas. De otro lado, se ha de cuidar la adecuación de las herramientas seleccionadas para que resulten viables, realistas, eficaces y eficientes (mantener bajos los costes operativos, facilitar el mantenimiento del sitio, etc.) a la hora de desempeñar su cometido. Estas exigencias se vinculan a la sostenibilidad de las mismas. El uso de herramientas ineficaces puede acarrear consecuencias negativas y la pérdida de oportunidades para el patrimonio, los visitantes y las partes interesadas.

Finalmente, y no por ello menos importante, están los principios orientados a los aspectos sociales que deben acompañar el diseño e implementación de estas herramientas. Así, destacan los valores de participación, inclusión, y la cooperación. Para garantizar la participación pública están los procesos participativos, instrumentos de gobernanza que van a acompañar el desarrollo de todas las herramientas anteriores ya que aseguran a largo plazo la sostenibilidad social de los proyectos, al facilitar la participación activa de la sociedad civil en los asuntos públicos. En particular, en este caso, en la puesta en valor turística del patrimonio. Este principio se inspira en estrategias de intervención transparentes, inclusivas y democráticas; sitúa a las personas en el centro de las políticas y los proyectos. ICOMOS (2011) señala que buscan el compromiso de las comunidades en los sectores del patrimonio cultural y 


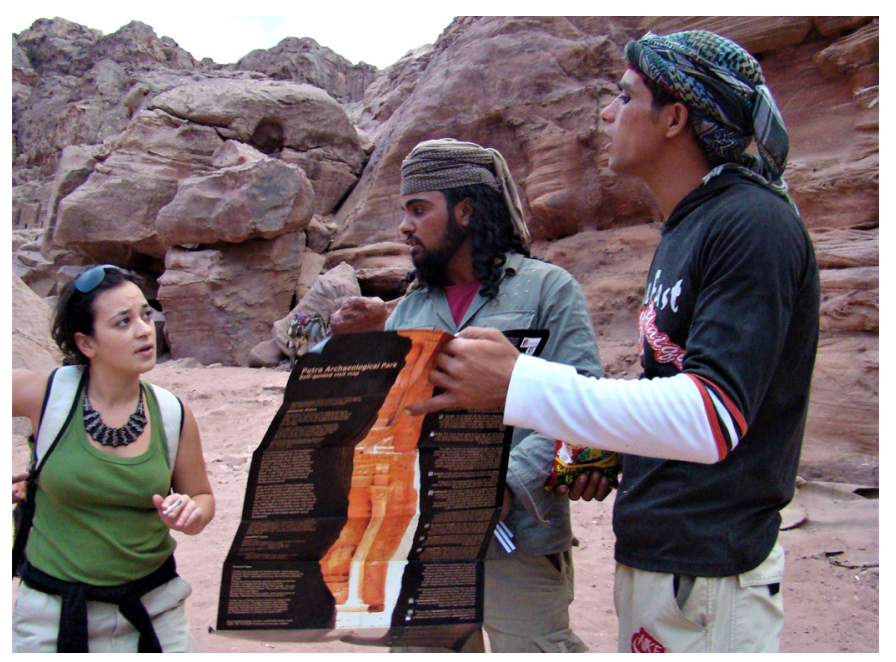

el turismo y el fomento de la creatividad, el desarrollo personal y el espíritu empresarial. Se considera que la apropiación del patrimonio por parte de las comunidades locales refuerza el tejido social y mejora su bienestar social. Por otra parte, la inclusión es un principio transversal, muy ligado al anterior, y necesario también en todos los proyectos de desarrollo del patrimonio ya que significa que todas las partes interesadas intervendrán de igual manera en los procesos participativos.

El principio de cooperación ha sido destacado por la OCDE (2020) en relación a la colaboración y coherencia que debe existir entre los diferentes estamentos gubernamentales y también haciendo referencia a la necesidad de involucrar al sector turístico (cooperación intersectorial) en la planificación estratégica. Por lo tanto, el compromiso proactivo, el entendimiento compartido y el trabajo en colaboración deben constituir una referencia para todos los actores institucionales y privados al abordar los procesos de planificación turística del patrimonio.

\section{REFLEXIONES FINALES}

Tras la presentación de diversas herramientas de planificación para la puesta en valor y gestión turística del patrimonio experimentadas por la autora y su equipo de investigación y los principios básicos para su correcta aplicación, se puede decir que los resultados obtenidos de su implementación han confirmado que el desarrollo turístico de los lugares donde se han implantado han contribuido a resolver problemas previos existentes en el sitio patrimonial, a mejorar la presentación del sitio patrimonial y la calidad de vida de los residentes. El hecho de trabajar sobre la base de los recursos patrimoniales de forma respetuosa y sostenible ha contribuido también a fomentar una 
conservación activa de los mismos y a estimular el aprecio de las comunidades locales por su patrimonio. Sin duda, no se vislumbra en el futuro otra fórmula de conocer y disfrutar el patrimonio que no sea desde una planificación eficiente, sostenible y resiliente.

Las herramientas se han ido refinando a lo largo de años de trabajo, pero sigue siendo un reto enfrentarse a un nuevo sitio patrimonial, ya que cada uno resulta siempre diferente a los anteriores. No obstante, los problemas suelen parecerse y las soluciones exitosas pueden extrapolarse con las adaptaciones necesarias ad hoc.

En estos momentos, y asumida la situación de crisis que ha conocido el sector turístico con ocasión de la pandemia de la COVID-19, el mayor reto en estos momentos, reside en dotar de la mayor resiliencia posible al sector y evitar la desconexión del público con el patrimonio. Las comunidades residentes necesitan mantener sus lazos identitarios vivos; los destinos necesitan los ingresos derivados del turismo; y los turistas necesitan alimentar su conocimiento y sus emociones. Todo esto será en parte posible si se planifican y gestionan los recursos patrimoniales al amparo de sólidas herramientas técnicas y principios éticos, sin generar unas expectativas que sobrepasen los umbrales de uso responsable de los mismos. De esta manera, los sitios tienen que ser capaces de planificar para prever las crisis, asimilar los impactos y los cambios con una respuesta eficiente y ofrecer siempre una experiencia memorable para los visitantes. 


\section{BIBLIOGRAFÍA}

- Aken, J.E. van (2004) Management Research Based on the Paradigm of the Design Sciences: The Quest for Field-Tested and Grounded Technological Rules. Journal of Management Studies, vol. 41(2), pp. 219-246

- Andaroodi, E. (2020) Analyzing the Infrastructures of Cultural Tourism in Heritage sites with an Emphasis on Architectural Design Elements. Journal of Art and Civilization of the Orient, vol. 8(27), pp. 61-74. Disponible en: http://www.jaco-sj.com/article_111396.html?lang=en [Consulta: 13/07/2021]

- Australian Government (2004) Steps to sustainable tourism. Planning a sustainable future for tourism, heritage and the environment. $1 .^{\mathrm{a}}$ ed. Canberra: Dept. of the Environment and Heritage, 66 p. Disponible en: https:// webarchive.nla.gov.au/awa/20050718170625/http://www. deh.gov.au/heritage/publications/sustainable-tourism/pubs/ steps.pdf [Consulta: 13/07/2021]

- Australian Government (2019) Environmental and Heritage Assessments. Last reviewed: 4 November 2019. Disponible en: https://www.agriculture.gov.au/forestry/ policies/rfa/about/process/environmental-heritage\#1 [Consulta: 13/07/2021]

- Baycan, T. y Girard, L.F. (2011) Heritage in socioeconomic development: Direct and indirect impacts. En ICOMOS 17th General Assembly, 2011-11-27/ 2011-12-02, Paris, France. Disponible en: http:// openarchive.icomos.org/id/eprint/1299/ [Consulta: 13/ 07/2021]

- Beck, L. y Cable, T. (1998) Interpretation for 21th Century. Fifteen Guiding Principles for Interpreting Nature and Culture. Champaign, IL, USA: Sagamore Publishing, $242 \mathrm{p}$.

- Beyer, D., Anda, M., Elber, B., Revell, G. y Spring, F. (2005) Best practice model for low-impact nature-based sustainable tourism facilities in remote areas. Gold Coast, Qld.: CRC for Sustainable Tourism, $44 \mathrm{p}$.

- Bowitz, E. y Ibenholt, K. (2009) Economic impacts of cultural heritage-Research and perspectives. Journal of Cultural Heritage, vol. 10(1), pp. 1-8

- Bucholz, J., Lackey, B., Gross, M., Zimmerman, R. (2015) The Interpreter Guidebook. Techniques for programs and presentations. 4. ${ }^{\mathrm{a}}$ ed. Stevens Point, Wisconsin: UWSP Foundation Press

- Carballo, R., Moreno-Gil, S., León, C. y Ritchie, J.R.B. (2015) La creación y promoción de experiencias en un destino turístico. Un análisis de la investigación y necesidades de actuación. Cuadernos de Turismo, n. ${ }^{\circ} 35$, enero-junio, pp. 75-94

- Comisión Europea (2011) Estrategia de la UE sobre la biodiversidad hasta 2020: nuestro seguro de vida y capital natural. $\operatorname{COM(2011)~} 244$ final. Disponible en: https://eur-lex.europa.eu/legal-content/ES/TXT/PDF /?uri=CELEX:52011DC0244\&from=CS [Consulta: 14/ 07/2021]

- Comisión Europea (2014) Hacia un enfoque integrado del patrimonio cultural europeo. $\operatorname{COM}(2014) 477$ final. Disponible en: https://eur-lex.europa.eu/legal-content/ES/ TXT/PDF/?uri=CELEX:52014DC0477\&from=DA [Consul ta: $14 / 07 / 2021]$

- De Ascaniis, S., Gravari-Barbas, M., y Cantoni, L. (2018) Tourism Management at UNESCO World Heritage Sites. Lugano: Università della Svizzera italiana. Disponible en: https://lms.fun-mooc.fr/assetv1:Paris1+16008+session01+type@asset+block@ MOOC_TmatUWHS_manual.pdf [Consulta:14/07/2021]

- Della Spina, L. (2019) Historical Cultural Heritage: Decision Making Process and Reuse Scenarios for the Enhancement of Historic Buildings. En: Calabrò, F., Della Spina, L., Bevilacqua, C. (ed.) New Metropolitan Perspectives. ISHT 2018. Smart Innovation, Systems and Technologies. Cham: Springer, pp. 442-453

- Eagles, P.F.J. y McCool, S.F. (2002) Tourism in National Parks and Protected Areas: Planning and Management. Wallingford: CABI Publishing, $320 \mathrm{p}$.

- European Commission (2017) European Tourism Indicators System for sustainable destination management. Disponible en: https://ec.europa.eu/growth/sectors/tourism/ offer/sustainable/indicators/index_en.htm [Consulta 14/07/2021]

- Grattan, N. (2004) ICCROM \& Public Advocacy: Over 10 years of working with teachers, students, the media, tourists, heritage professionals, and the general public. International Centre for the Study of the Preservation and Restoration of Cultural Property. Disponible en: https://www.iccrom.org/ sites/default/files/ICCROM 03 PublicAdvocacy-It en.pdf [Consulta: 14/07/2021]

- Gunn, C.A. y Var, T. (2002) Tourism Planning. 4th ed. New York: Routledge, 464 p.

- Hall, C.M. y McArthur, S. (1998) Integrated heritage management: Principles and Practice. London: Stationery Office, $250 \mathrm{p}$.

- Ham, S. (1992) Environmental Interpretation: A Practical Guide for People with Big Ideas and Small Budgets. Golden, CO, USA: Fulcrum Publishing

- House of Commons. ODPM: Housing, Planning, Local Government and the Regions Committee (2004) The Role of Historic Buildings in Urban Regeneration: Eleventh 
Report of Session 2003-04. London: The Stationery Office Limited, vol. I. Disponible en: https://publications. parliament.uk/pa/cm200304/cmselect/cmodpm/47/47.pdf [Consulta: 14/07/2021]

- Historic England (2018) Heritage and the Economy 2018. Disponible en: https://historicengland.org.uk/content/ heritage-counts/pub/2018/heritage-and-the-economy-2018 [Consulta: 14/07/2021]

- ICOMOS (2008) The ICOMOS Charter for the Interpretation and Presentation of Cultural Heritage Sites. 16th General Assembly of ICOMOS, Quebec, Canada, 2008. Disponible en: http://icip.icomos.org/downloads/ ICOMOS_Interpretation_Charter_ENG_04_10_08.pdf [Consulta: 14/07/2021]

- ICOMOS (2011a) Declaración de París sobre el Patrimonio como Motor del Desarrollo. 17a Asamblea General del ICOMOS, París, noviembre de 2011. Disponible en: https://www.monumentos.gob.cl/sites/ default/files/articles-55372_doc_pdf.pdf [Consulta 14/ 07/2021]

- ICOMOS (2011b) Guidance on Heritage Impact Assessments for Cultural World Heritage Properties. Disponible en: http://openarchive.icomos.org/id/e print/266/1/ICOMOS_Heritage_Impact_Assessment 2010.pdf [Consulta 14/07/2021]

- Instituto para la Calidad Turística Española (2020) Medidas para la reducción de contagio por el coronavirus SARSCoV-2. Museos y Sitios patrimoniales. Directrices y recomendaciones. Disponible en: https://www.mincotur. gob.es/es-es/COVID-19/turismo/GuiasSectorTurismo/ Guias_de_turismo.pdf [Consulta 14/07/2021]

- International Council of Museums (2020a) Museums and the Covid-19 crisis: 8 steps to supporting community resilience. Disponible en: https://icom.museum/es/news/ museos-y-covid-19-8-pasos-para-apoyar-la-resiliencia-delas-comunidades/ [Consulta 14/07/2021]

- International Council of Museums (2020b) Recommendations for the conservation of museum collections. Disponible en: https://icom.museum/es/news/ recomendaciones-par-la-conservacion-de-la-coleccionesen-los-museos/ [Consulta 14/07/2021]

- International Council of Museums (s.f.) Awarenessraising. En: Observatory on Illicit Traffic in Cultural Goods. Disponible en: https://www.obs-traffic.museum/awarenessraising [Consulta 04/05/2021]

- Kim, J.J. y Fesenmaier, D.R. (2015) Designing tourism places: Understanding the tourism experience through our senses. En: 2015 International Conference of Travel and Tourism Research Association: Advancing Tourism Research Globally. Disponible en: https://scholarworks. umass. edu/cgi/viewcontent.cgi?article $=1041 \&$ context=ttra [Consulta 14/07/2021]

- Labadi, S., Giliberto, F., Rosetti, I., Shetabi, L., Yildirim,
E. (2021) Heritage and the Sustainable Development Goals: Policy Guidance for Heritage and Development Actors. Paris: ICOMOS, $69 \mathrm{p}$.

- Lähdesmäki, T. (2014) The EU'S Explicit and Implicit Heritage Politics. European Societies, vol. 16(3), pp. 401421. Disponible en: https://www.tandfonline.com/doi///10.1 080/14616696.2014.894547?scroll=top\&needAccess=true [Consulta 14/07/2021]

- Ley 16/1985, de 25 de junio, del Patrimonio Histórico Español. Boletín Oficial del Estado, n. ${ }^{\circ} 155$, de 29/06/1985. Disponible en: https://www.boe.es/eli/es/l/1985/06/25/16/ con [Consulta 14/07/2021]

- Manrique, C., Tazim, J. y Warden, R. (2016) Heritage Tourism and Conservation: A Cultural Resilience Bridge? En Munar, A.M y Jamal, T. (ed.) Tourism Research Paradigms: Critical and Emergent Knowledges. Bingley: Emerald Publishing

- Martos Molina, M. (2016) Herramientas para la gestión turística del patrimonio cultural. Gijón: Trea

- Ministerio de Cultura y Deporte. Dirección General de Bellas Artes (2020) Planificación de medidas para la reapertura de los museos de titularidad y gestión estatal dependientes de la Dirección General de Bellas Artes. Disponible en: https://www.culturaydeporte.gob.es/dam/ jcr:6f409c61-dac0-4d66-a3f8-781ebbbcf868/planificacin-de-medidas-para-la-reapertura-de-los-museos-detitularidad-y-gesti-n-estatal-dependientes-de-la-direcci-ngeneral-de-bellas-artes.pdf [Consulta: 14/07/2021]

- Ministerio de Cultura y Deporte. IPCE (2020) Recomendaciones sobre procedimientos de desinfección en bienes culturales con motivo de la crisis por COVID-19. Disponible en: https://ipce.culturaydeporte.gob.es/dam/ jcr:3cf1e6b5-1925-440d-a514-3c60f1edadc9/anexo-recomendaciones-ipce-patrimonio-covid-19--1-.pdf [Consulta 14/07/2021]

- Moscardo, G. (2019) Connecting people with experiences. En: McCool, S.F. y Bosak, K. (ed.) A research agenda for sustainable tourism. Cheltenham, GBR: Edward Elgar, pp. 70-89

- OCDE e ICOM (2019) Cultura y Desarrollo Local: Maximizar el Impacto. Una guía para gobiernos locales, comunidades y museos. Disponible en: https://www.oecd. org/cfe/leed/OECD-ICOM-GUIDE-MUSEUMS-ES.pdf [Consulta 14/07/2021]

- Organización de Naciones Unidas (2015) Transformar nuestro mundo: la Agenda 2030 para el Desarrollo Sostenible. Resolución de la Asamblea General, 25/09/2015, 70/1. Disponible en: https://www.agenda2030 gob.es/recursos/docs/APROBACION_AGENDA_2030.pdf [Consulta 14/07/2021]

- Pearce, P. (1991) Analysing tourist attractions. Journal of Tourism Studies, vol. 2(1), pp. 46-55 
- Pedersen, A. (ed.) (2002) Managing Tourism at World Heritage Sites: a Practical Manual for World Heritage Site Managers. Paris: UNESCO World Heritage Centre. Disponible en: http://whc.unesco. org/sustainabletourismtoolkit/sites/default/files/1.\%20 UNESCO $\% 20 \% 282002 \% 29 \% 20$ WH\%20Paper\%201\%20 Managing \%20Tourism\%20at\%20WH\%20Sites.PDF [Consulta 14/07/2021]

- Peltier, D. (2017) Nearly Half of UNESCO Sites don't have Plans to Manage Overtourism Challenges. En: Skift Corporate. Disponible en: https://skift.com/2017/04/19/ nearly-half-of-unesco-sites-dont-have-plans-to-manageovertourism-challenges/ [Consulta 14/07/2021]

- Pendlebury, J. y Porfyriou, H. (2017) Heritage, urban regeneration and place-making. Journal of Urban Design, vol. 22(4), pp. 429-432. Disponible en: https://www. tandfonline.com/doi/full/10.1080/13574809.2017.1326712 [Consulta 14/07/2021]

- Reitsamer, B.F. y Brunner-Sperdin, A. (2015) Tourist destination perception and well-being: What makes a destination attractive? Journal of Vacation Marketing, vol. 23(1), pp. 55-72

- Richards, G. y Munsters, W. (ed.) (2010) Cultural tourism research methods. sl.: CAB

- Scott, N., Gao, J., y Ma, J. (2017) Visitor Experience Design. sl.: CABI, 284 p.

- Shimray, S.R. (2019) Ways to Create Awareness on Cultural Heritage: An overview. Library Philosophy and Practice, Summer 4-26-2019. Disponible en: https:// digitalcommons.unl.edu/libphilprac/2577 [Consulta: 14 /07/2021]

- Stankey, G. y Manning, R. (1986) Carrying Capacity of Recreation Settings. A Literature Review. The President's Commission on Americans Outdoors. Washington, DC: U.S. Government Printing Office

- Tilden, F. (1957) Interpreting our Heritage. Chapel Hill, USA: University of North Carolina Press, $224 \mathrm{p}$.

- UNEP y UNWTO (2005) Making Tourism more Sustainable: A Guide for Policy Makers. Disponible en: https://wedocs.unep.org/bitstream/ handle/20.500.11822/8741/-Making\%20Tourism\%20 More\%20 Sustainable_\%20 A\%20Guide \% 20 for $\% 20$ Policy $\% 20$ Makers-2005445.pdf?sequence= 3\&isAllowed=y [Consulta 14/07/2021]

- UNEP y CBD (2010) Plan Estratégico para la Diversidad Biológica 2011-2020 y las Metas de Aichi para la Diversidad Biológica. UNEP/CBD/COP/DEC/X/2, 27 de octubre de 2010. Disponible en: https://www.cbd.int/doc/decisions/ cop-10/cop-10-dec-02-es.pdf [Consulta 14/07/2021]

- UNESCO. Centro de Patrimonio Mundial (2005) Directrices Prácticas para la aplicación de la Convención del Patrimonio Mundial. WHC.05/2, 2 de febrero de 2005.
Disponible en: https://whc.unesco.org/archive/opguide05es.pdf [Consulta 14/07/2021]

- UNESCO. World Heritage Committee (2011) World Heritage Tourism Programme. WHC-12/36.COM/5E, Paris, 11 May 2012. Disponible en: https://whc.unesco. org/archive/2012/whc12-36com-5E-en.pdf [Consulta 14/07/2021]

- UNESCO. World Heritage Committee (2014) Alentar la resiliencia. Patrimonio Mundial, n. ${ }^{\circ}$ 74, pp. 4-63. Disponible en: http://unesdoc.unesco.org/ images/0023/002316/231678s.pdf [Consulta 14/07/20 21]

- UNESCO (s.f.) UNESCO World Heritage Sustainable Tourism Online Toolkit. Disponible en: http://whc.unesco. org/sustainabletourismtoolkit/ [Consulta 14/07/2021]

- UNWTO (s.f..) Product development. Disponible en: https://www.unwto.org/tourism-development-pro ducts [Consulta 22/05/2021]

- Viñals, M.J., Morant, M. y Teruel, L. (2014): Confort psicológico y experiencia turística. Casos de estudio de espacios naturales protegidos de la Comunidad Valenciana (España). Boletín de la Asociación de Geógrafos Españoles, n. ${ }^{\circ} 65$, pp. $293-316$

- Viñals, M.J., Mayor, M., Martínez Sanchis, I., Teruel, L., Alonso-Monasterio, P. y Morant, M. (2017) Turismo sostenible y patrimonio: Herramientas para la planificación y gestión. Valencia: Universitat Politècnica, 191 p. Disponible en: https://riunet.upv.es/handle/10251/91732 [Consulta 14/07/2021]

- Viñals, M.J. y Teruel, L. (2021) La perspectiva de la sostenibilidad medioambiental en los estudios de máster y doctorado en turismo en España. Cuadernos de Turismo, n. ${ }^{\circ}$ 47, pp. 487-513. Disponible en: https://revistas.um.es/ turismo/article/view/474511 [Consulta 14/07/2021]

- Wight, P. (1998) Tools for sustainability analysis in planning and managing tourism and recreation in the destination. En: Hall, M.C. y Lew, A.A. (ed.) Sustainable Tourism: A Geographical Perspective. New York: Longman Limited, pp. 35-48

- Yang, C.H. y Lin, H.Y. (2014) Revisiting the relationship between World Heritage Sites and tourism. Tourism Economics, vol. 20(1), pp. 73-86 